\title{
BMJ Open Assessment of patient-reported outcomes after polytrauma - instruments and methods: a systematic review
}

\author{
Michaela Ritschel (D) , ${ }^{1}$ Silke Kuske, ${ }^{2}$ Irmela Gnass, ${ }^{3}$ Silke Andrich, ${ }^{1,4}$ \\ Kai Moschinski, ${ }^{1}$ Sandra Olivia Borgmann, ${ }^{1,4}$ Annegret Herrmann-Frank, ${ }^{1}$ \\ Maria-Inti Metzendorf, ${ }^{5}$ Charlotte Wittgens, ${ }^{1}$ Sascha Flohé, ${ }^{6,7}$ Johannes Sturm, ${ }^{8}$ \\ Joachim Windolf, ${ }^{7}$ Andrea Icks ${ }^{1,4}$
}

To cite: Ritschel M, Kuske S, Gnass I, et al. Assessment of patient-reported outcomes after polytrauma instruments and methods: a systematic review. BMJ Open 2021;11:e050168. doi:10.1136/ bmjopen-2021-050168

- Prepublication history and additional supplemental material for this paper are available online. To view these files, please visit the journal online (http://dx.doi.org/10.1136/ bmjopen-2021-050168)

Received 11 February 2021 Accepted 14 September 2021

Check for updates

(C) Author(s) (or their employer(s)) 2021. Re-use permitted under CC BY-NC. No commercial re-use. See rights and permissions. Published by BMJ.

For numbered affiliations see end of article.

Correspondence to

Michaela Ritschel;

michaela.ritschel@hhu.de

\section{ABSTRACT}

Objectives We (1) collected instruments that assess health-related quality of life (HRQoL), activities of daily living (ADL) and social participation during follow-up after polytrauma, (2) described their use and (3) investigated other relevant patient-reported outcomes (PROs) assessed in the studies.

Design Systematic Review using the Preferred Reporting Items for Systematic Review and Meta-Analysis guideline.

Data sources MEDLINE, Embase, CINAHL, PsycINFO, CENTRAL, as well as the trials registers ClinicalTrials.gov and WHO ICTRP were searched from January 2005 to April 2018.

Eligibility criteria All original empirical research published in English or German including PROs of patients aged 18-75 years with an Injury Severity Score $\geq 16$ and/ or an Abbreviated Injury Scale $\geq 3$. Studies with defined injuries or diseases (e.g. low-energy injuries) and some text types (e.g. grey literature and books) were excluded. Systematic reviews and meta-analyses were excluded, but references screened for appropriate studies.

Data extraction and synthesis Data extraction, narrative content analysis and a critical appraisal (e.g. UK National Institute for Health and Care Excellence) were performed by two reviewers independently.

Results The search yielded 3496 hits; 54 publications were included. Predominantly, HRQoL was assessed, with Short Form-36 Health Survey applied most frequently. $A D L$ and (social) participation were rarely assessed. The methods most used were postal surveys and single assessments of PROs, with a follow-up period of one to one and a half years. Other relevant PRO areas reported were function, mental disorders and pain.

Conclusions There is a large variation in the assessment of PROs after polytrauma, impairing comparability of outcomes. First efforts to standardise the collection of PROs have been initiated, but require further harmonisation between central players. Additional knowledge on rarely reported PRO areas (e.g. (social) participation, social networks) may lead to their consideration in health services provision. PROSPERO registration number CRD42017060825.
Strengths and limitations of this study

- This systematic review was based on a comprehensive search strategy and conducted according to a registered and published protocol.

- First systematic review that provides an overview of patient-oriented instruments used in research after polytrauma.

- Throughout the review process, we followed the Preferred Reporting Items for Systematic Review and Meta-Analysis guideline.

- A limitation might be the restriction of the search period and the language.

\section{INTRODUCTION}

Severe injuries represent a leading cause of death and permanent disability. ${ }^{1}$ In the central European region, severely injured people are referred to as having a 'polytrauma' or being 'polytraumatised'.' A polytrauma is defined as at least two severe injuries in different body regions or organ systems, at least one of which is potentially life-threatening by itself or in combination with others, with an Injury Severity Score (ISS) $\geq 16 .{ }^{1-4}$ According to the TraumaRegister DGU®, a German registry that covers patients with severe injuries, the number of patients with polytrauma (ISS $\geq 16$ ) was 15651 in $2019 .{ }^{5}$ Most affected were men $(72 \%)$ with a mean age of 46.5 years. ${ }^{6}$

The survival rates after polytrauma have increased lately, bringing the quality of survival into the focus of research. One year after polytrauma, survivors often fail to reach pretraumatic status due to persisting medical problems. ${ }^{7}$ Disabilities such as respiratory problems, paraplegia or tetraplegia, prevent $40 \%$ from returning to their former workplace. ${ }^{8}$ They also have an impact on socioeconomic aspects and quality of life $^{9-11}$ Therefore, it is crucial to reduce the short-term and long-term burden after 
polytrauma. $^{911}$ In this context, the patients' perspective on polytrauma outcomes focussing on psychological, physical and social factors is getting more important for the patients themselves, their relatives and healthcare professionals. ${ }^{1112}$ Evaluating these patient-reported outcomes (PROs) is essential to complete the holistic assessment of relevant clinical outcomes after injury from a patient's perspective.

To assess the impact of polytrauma on health-related quality of life (HRQoL) and other important PROs, one must consult the person affected directly. ${ }^{12} 13 \mathrm{HRQOL}$ is already being recorded in registers like the Australian Victoria State Trauma Registry. The German TraumaRegister DGU® will also complement its assessment with HRQoL. ${ }^{14}$ Activities of daily living (ADL), defined as basic activities to fulfil independent living, along with physical and psychological needs, are meaningful outcome parameters in case of postpolytrauma impairment. In recent years, the concept of social participation has gained more attention in the political context ${ }^{15}$ and was therefore included in the review as an outcome of interest, along with HRQoL and ADL. Several working groups have controversially discussed which tools should be applied to assess PROs after polytrauma, at which time points, and in which way. ${ }^{13}$ 16-24 However, guidelines with clear recommendations are lacking, ${ }^{13}$ and no systematic review could be identified.

Therefore, the aim of this systematic review was to:

1. collect instruments assessing HRQoL, ADL and social participation during follow-up after polytrauma.

2. describe their application in detail (e.g. duration of follow-up period, frequency of application and time point of measurements within the follow-up period).

3. investigate which other relevant PROs are additionally assessed in included studies (e.g. pain, depression, anxiety and cognitive function) without detailed analysis.

\section{METHODS}

This systematic review was conducted in line with the Preferred Reporting Items for Systematic Review and Meta-Analysis (PRISMA) guideline (online supplemental file 1$).^{25}$

\section{Data sources and search strategy}

The search was conducted in MEDLINE, Embase, CINAHL (Cumulative Index to Nursing and Allied Health Literature), PsycINFO, CENTRAL (Cochrane Central Register of Controlled Trials), the trials registers ClinicalTrials. gov and WHO ICTRP (WHO International Clinical Trials Registry Platform), initially covering the period from 1 January 2005 until 3 August 2016, with a later update of the search until 5 April 2018. The search period was chosen because since 2005 interest in HRQoL in research and its implication in practice has been growing. ${ }^{26}$ As one of our main aims was to collect instruments measuring HRQoL, we decided to include publications beginning with 2005. Our approach is supported by the emerging importance of PROs in clinical research and their relevance to the future as a complement to clinical data. ${ }^{27}$ Furthermore, the search period was selected to capture the most recent developments in research on PROs.

In addition, reference lists of eligible publications were examined. Textwords (tw) and MeSH-terms ( $\mathrm{mh}$ ) like 'polytrauma' (tw), 'multiple trauma' (mh), 'quality of life' (mh), 'activities of daily living' (tw), 'social participation' (mh) and 'pain' (mh) were used. The development of the search strategy was outlined in the study protocol ${ }^{28}$ (online supplemental file 2) and is provided in more detail in online supplemental file 3 .

\section{Inclusion and exclusion criteria}

The publications included primarily investigated PROs of patients aged 18-75 years with an ISS $\geq 16$ and/or an Abbreviated Injury Scale (AIS) $\geq 3$ during a clearly defined follow-up period. All original empirical research published in English or German was included. Publications examining special types of injury or illness-for example, low-energy injuries, single or mono injuries, burn injuries, war injuries or cancer-were excluded. We also excluded some publication types (grey literature, books, abstracts and editorials). Systematic reviews and meta-analyses were not included, too, but screened to identify further appropriate studies. More details about the inclusion and exclusion criteria were published in the study protocol. ${ }^{28}$

\section{Selection of publications and studies}

Four teams with two reviewers each (MR-IG; KM-SK; MR-SOB and AI-AHF) screened the title and abstracts independently. To foster the process of eligibility decisions, the inclusion or exclusion of the first 50 publications was discussed by two reviewers (MR-IG). In a next step, four teams with two reviewers each (MRIG; KM-SK; MR-SOB and KM-SOB) independently screened the full texts of the remaining publications for final inclusion. A third reviewer (MR, SK or IG) solved disagreements regarding the inclusion of publications for full-text screening and their final inclusion in this review. We identified publications relating to the same study and/or population. For this purpose, extensive research was conducted, and authors of the corresponding publications were contacted. The section 'Characteristics of included publications' outlines how we approached publications dealing with different research questions of the same study, comprising subpopulations drawn from a superior study population, reporting subprojects of a study project or presenting results of the same research question at different follow-up periods.

\section{Data extraction and analysis}

Data extraction was performed according to the requirements of Cochrane reviews. ${ }^{29}$ For the first and second aim, two researchers (MR-IG) used a piloted data extraction sheet independently comprising the 
following: first author, publication year and country, study design, aim of the study (objective), study population, treatment, applied instruments (incl. modifications), time of measurements, length of follow-up period, method of assessment (application), study results and results of the critical appraisal. Regarding the third aim, the other reported PROs were extracted and categorised in a separate extraction sheet. Narrative content analysis was performed regarding the assessment of HRQol, ADL and social participation as well as further reported PROs.

\section{Critical appraisal}

Teams with two reviewers each (MR, IG, SK, KM and SOB) independently assessed the methodological quality and the risk of bias in each study type using standardised checklists of the UK National Institute for Health and Care Excellence (NICE) ${ }^{3031}$ Scottish Intercollegiate Guidelines Network (SIGN) ${ }^{32}$ or the MixedMethod Appraisal Tool. ${ }^{33}$ Discrepancies were resolved by discussion between the reviewers or by a third reviewer.

\section{Patient and public involvement statement}

Patients were not involved in the design and implementation of this systematic review.

\section{RESULTS}

\section{Search results}

In total, 3485 references were retrieved. After a title and abstract screening as well as a full-text screening, further 11 records were identified by backward citation tracking. Finally, 54 eligible publications were included for data extraction (figure 1).

\section{Characteristics of included publications}

The publications $(\mathrm{n}=54)$ most often came from Germany $(\mathrm{n}=15,28 \%)$ and the Netherlands $(\mathrm{n}=11,20 \%)$; rarely from Austria, Denmark, France, Japan, Poland, Spain and Sweden (each $n=1,2 \%$ ). One study has been carried out in Germany and Austria, another one in Europe, Asia, Australia, Africa, North-America and South-America. The publications primarily reported monocentric studies $(\mathrm{n}=44,81 \%)$ and predominately comprised prospective cohort studies $(\mathrm{n}=26,48 \%)$ (table 1$)$.

The number of participants varied between $8^{34}$ and $7612,{ }^{35}$ with an average age of $24.6 \pm 12.1^{36}$ to $53.9 \pm 18.8^{37}$ years and a proportion of men between $37.5 \%{ }^{34}$ and $84 \% .^{38}$ The mean ISS ranged between $3.9 \pm 1.7^{39}$ and 56.8 points ${ }^{4041}$ and the AIS-reported in 18 publications-between zero and five points. Information regarding treatment of injuries was provided in $\mathrm{n}=31$ publications (table 1 ).

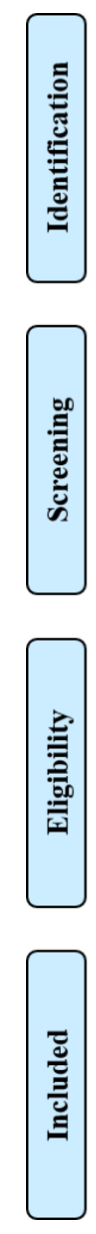

$$
\begin{gathered}
\text { Records identified through database } \\
\text { searching }
\end{gathered}
$$$$
(\mathrm{n}=3485)
$$

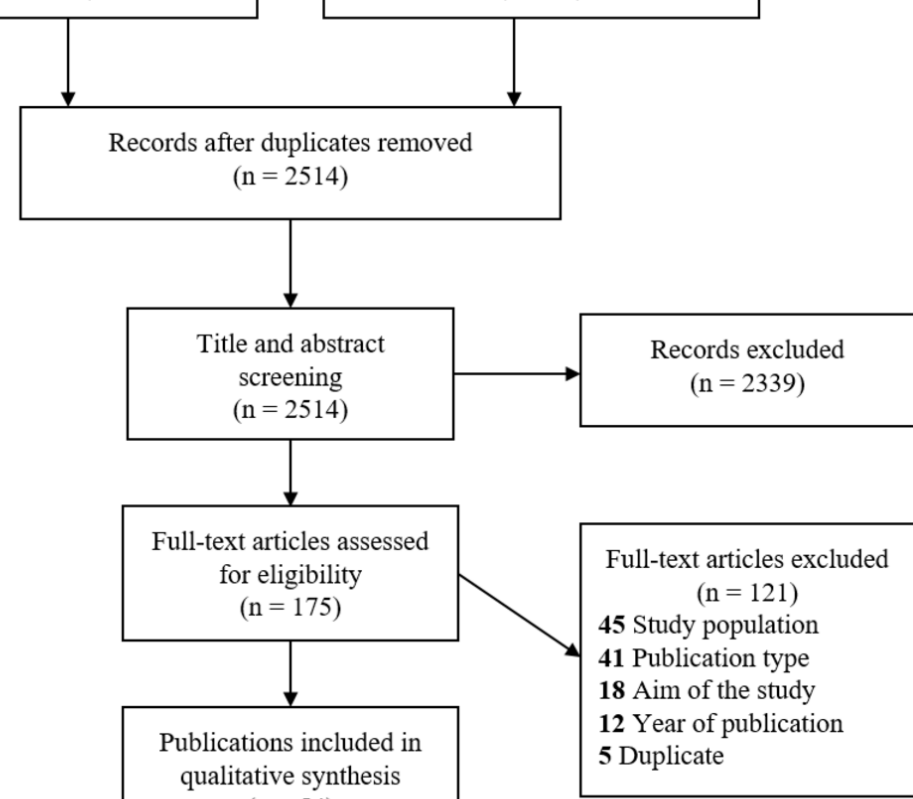

$(\mathrm{n}=54)$

Figure 1 Flow chart 


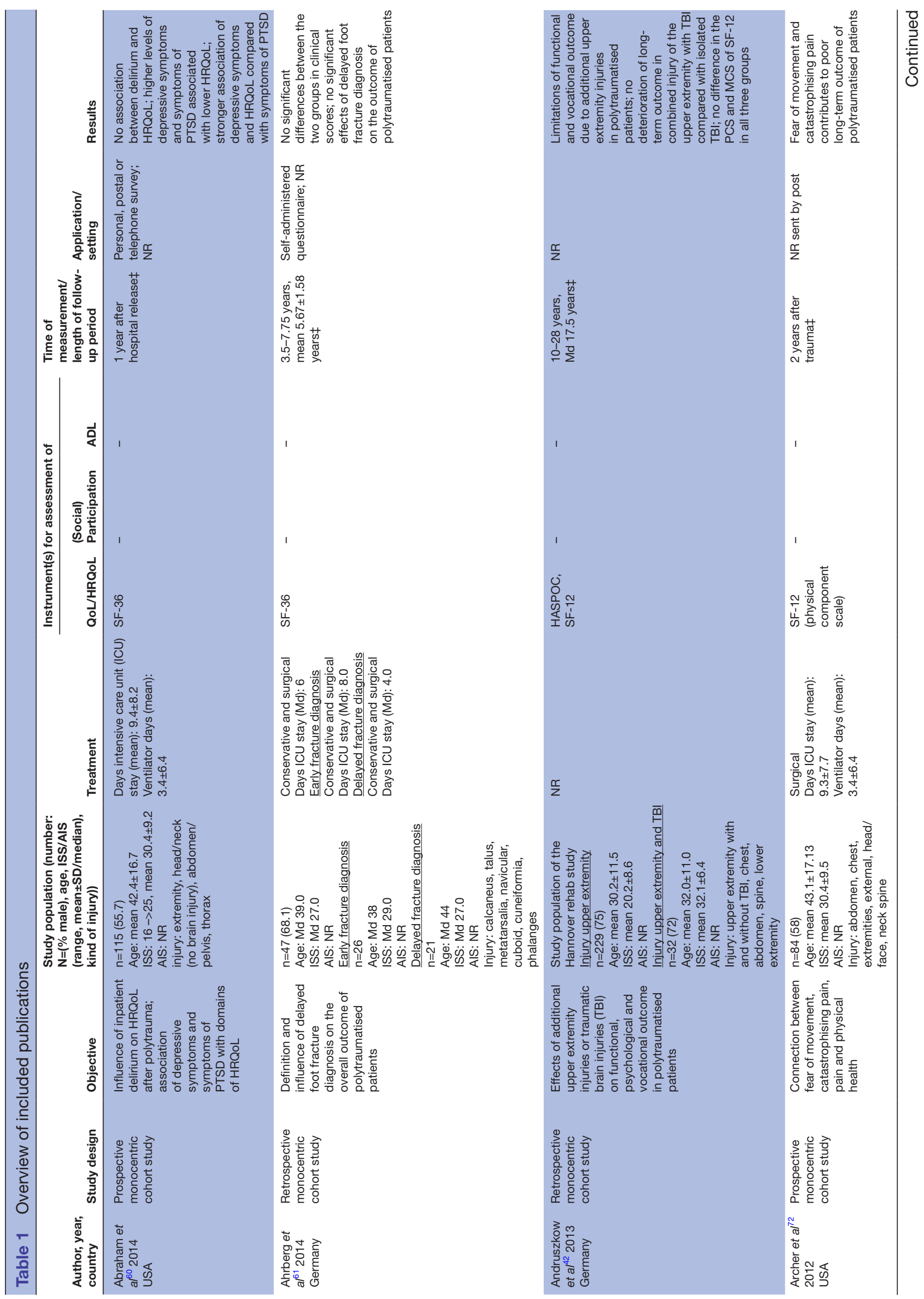



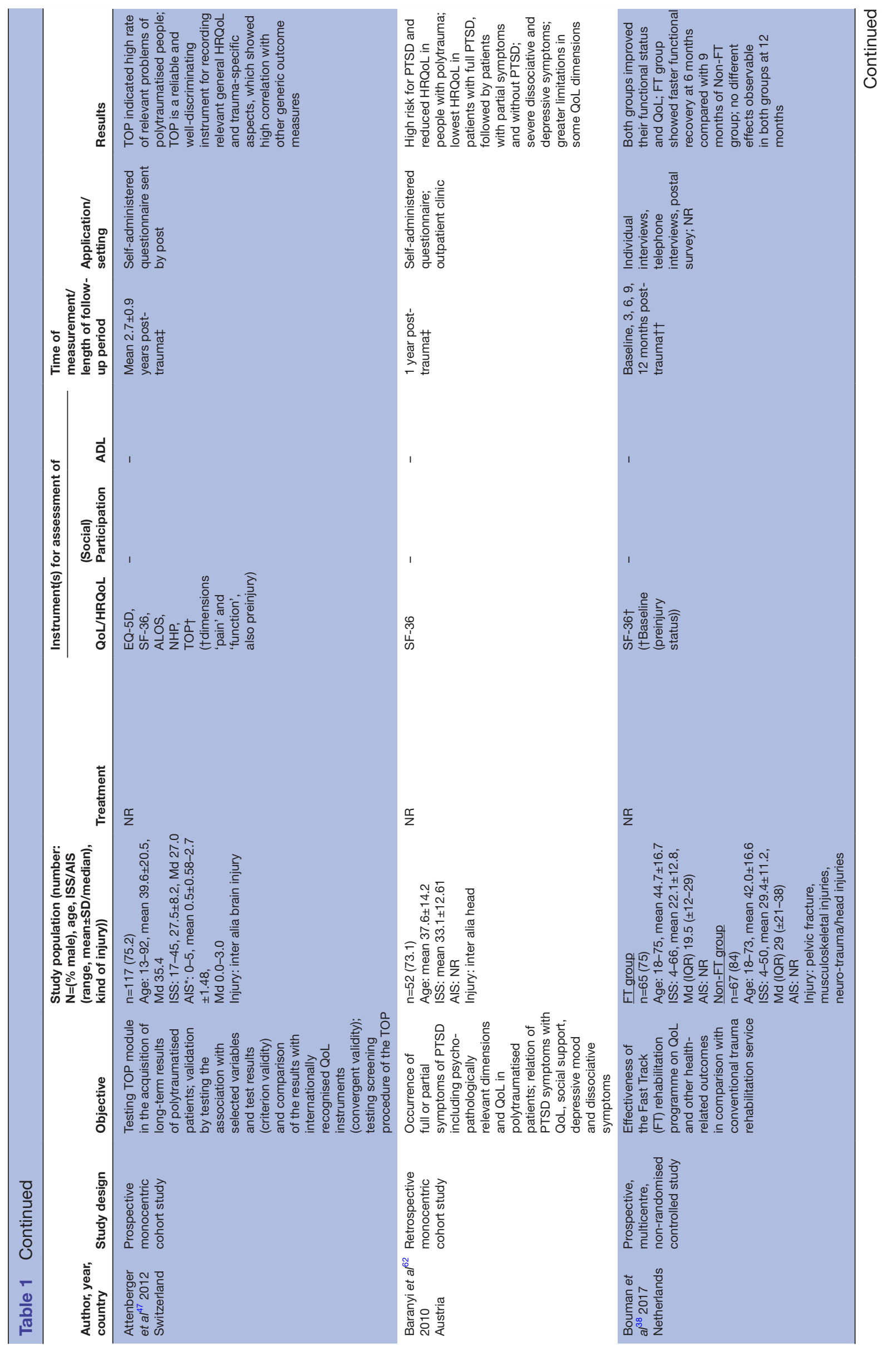


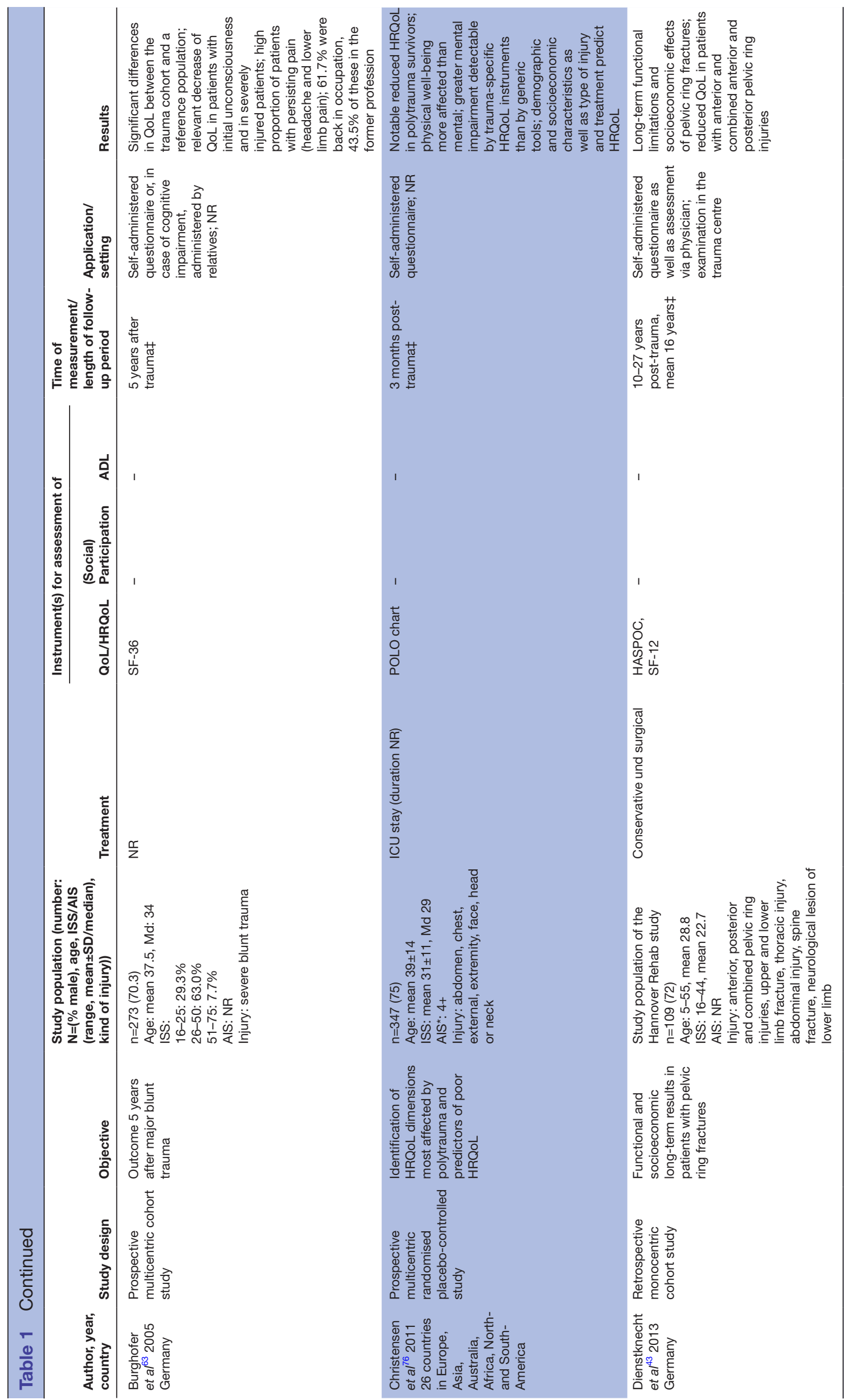




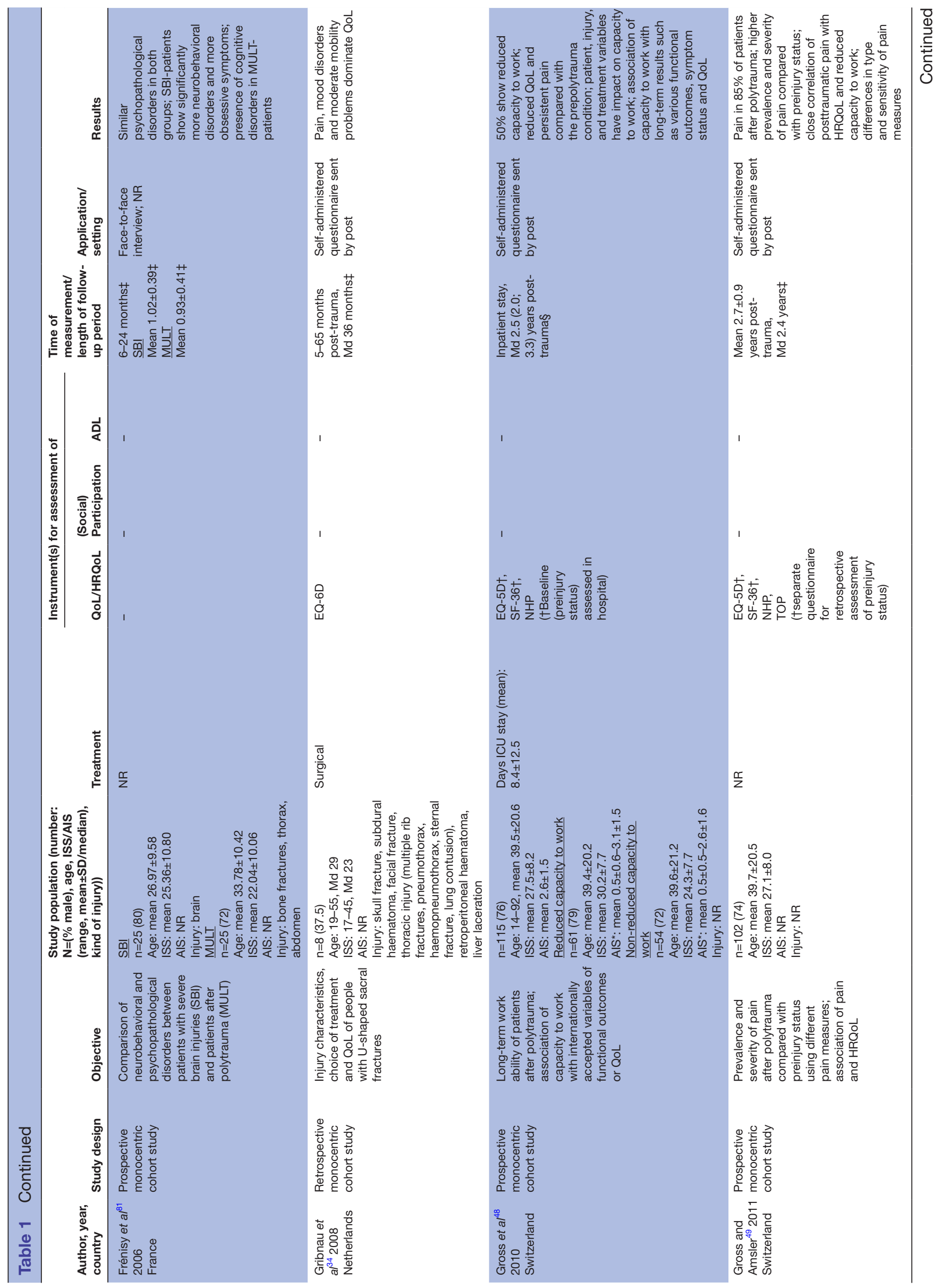




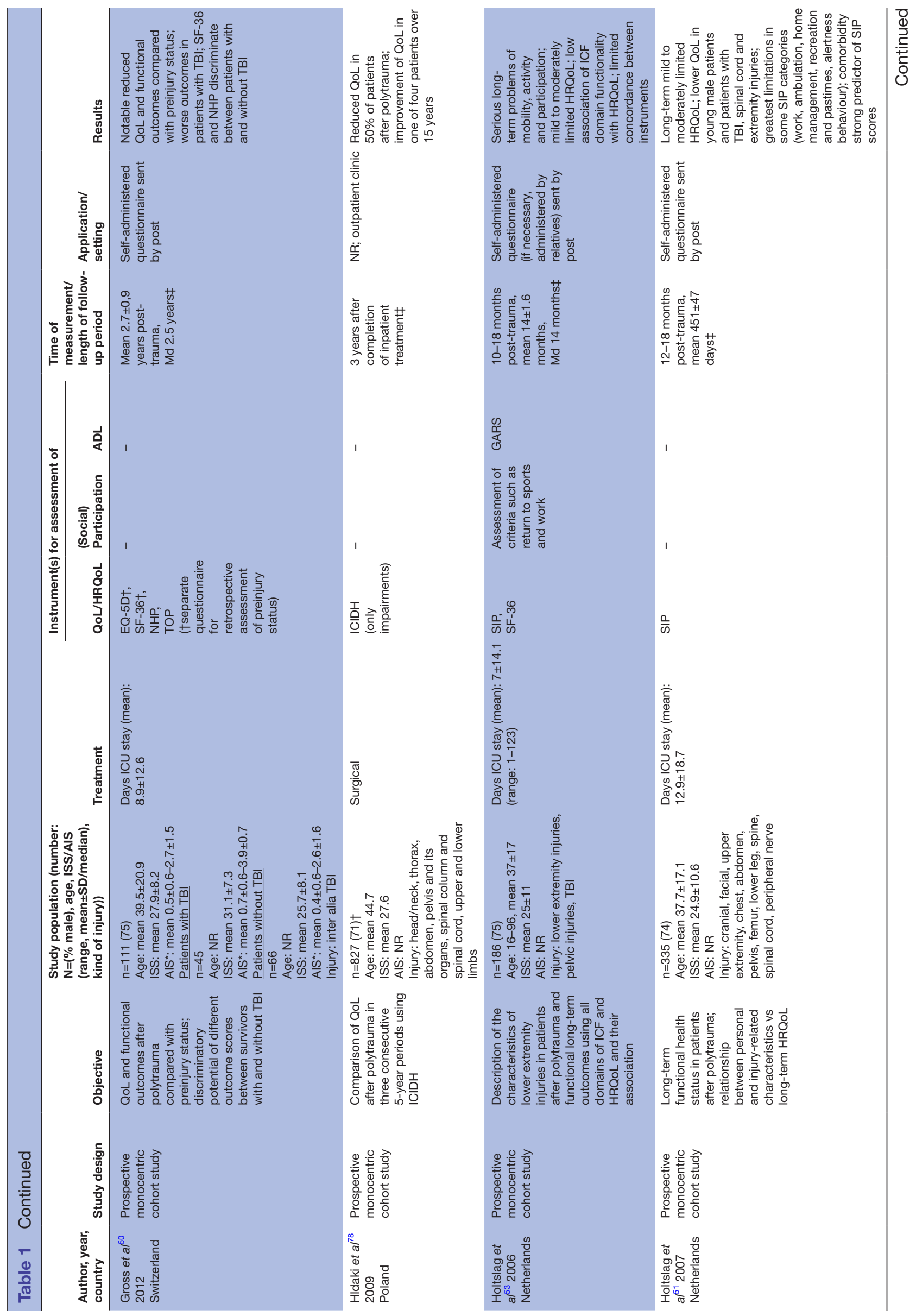




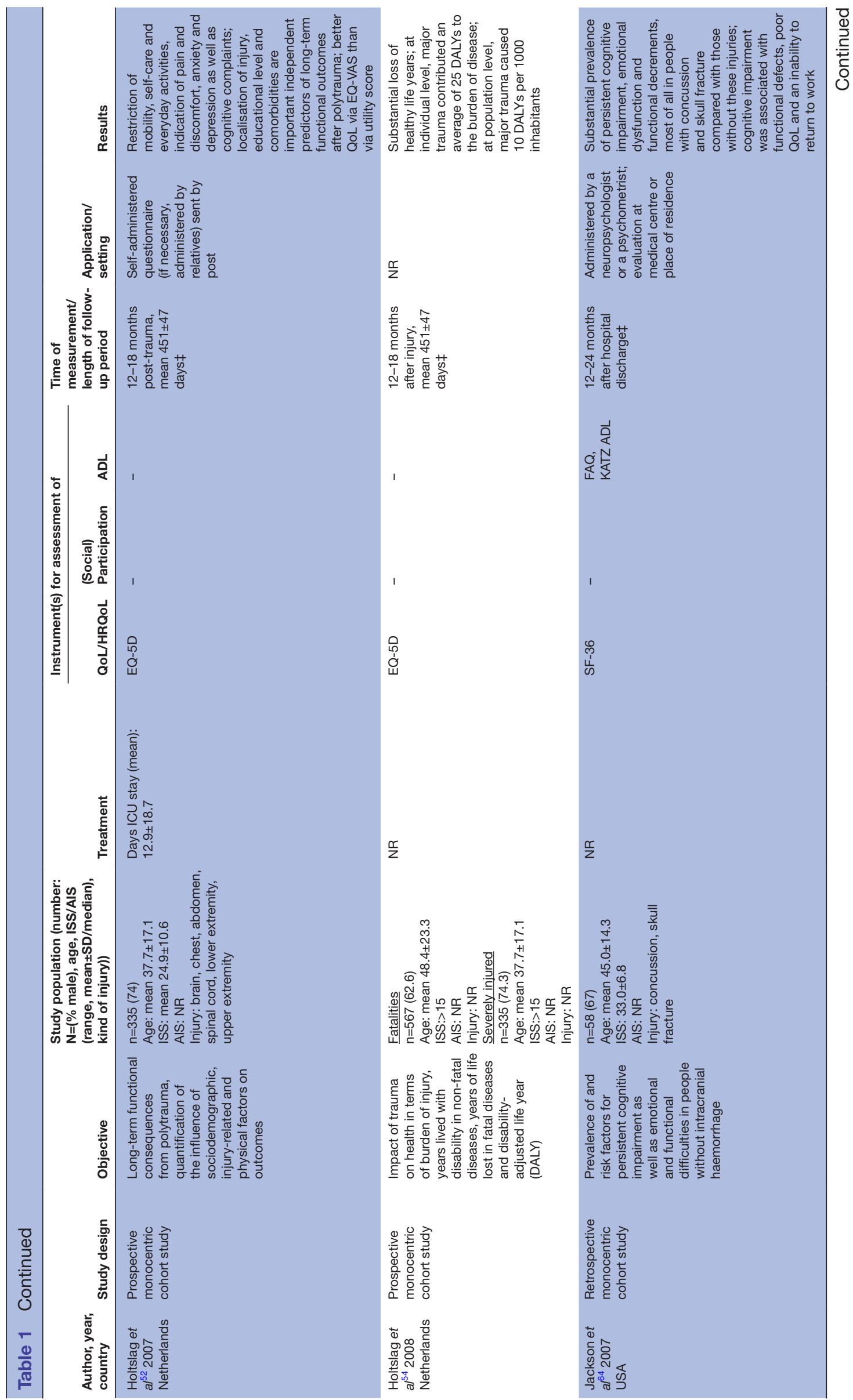




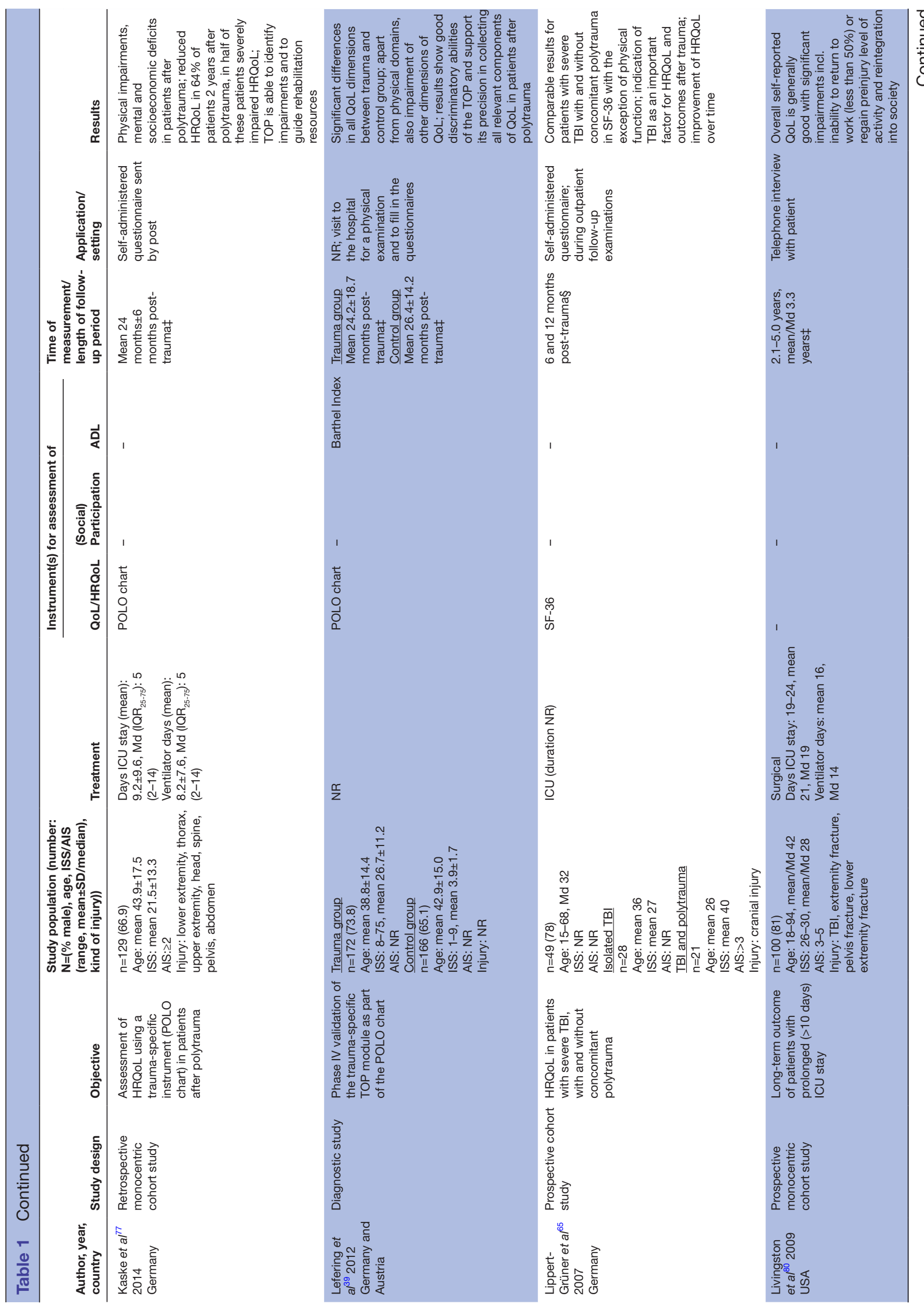




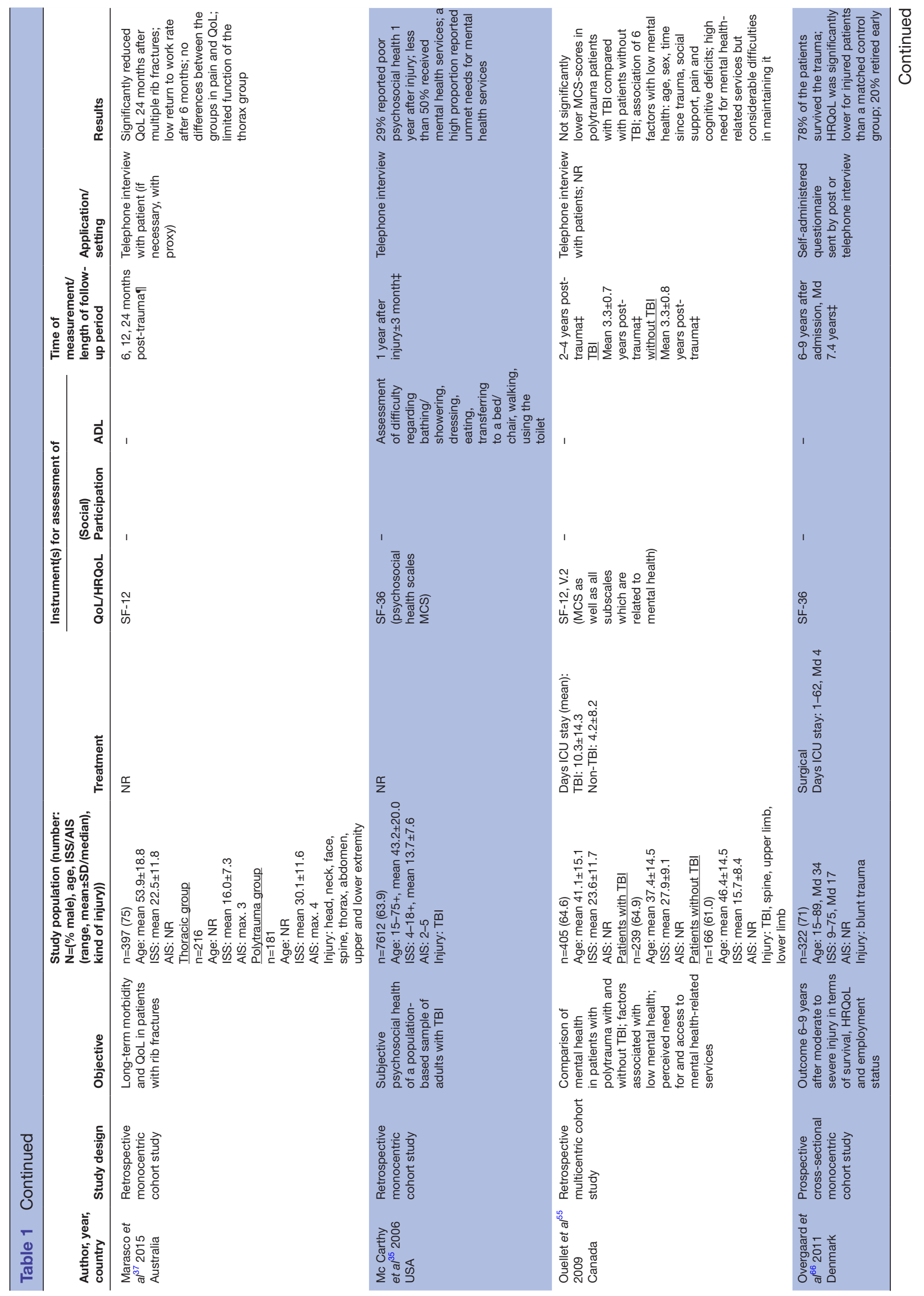




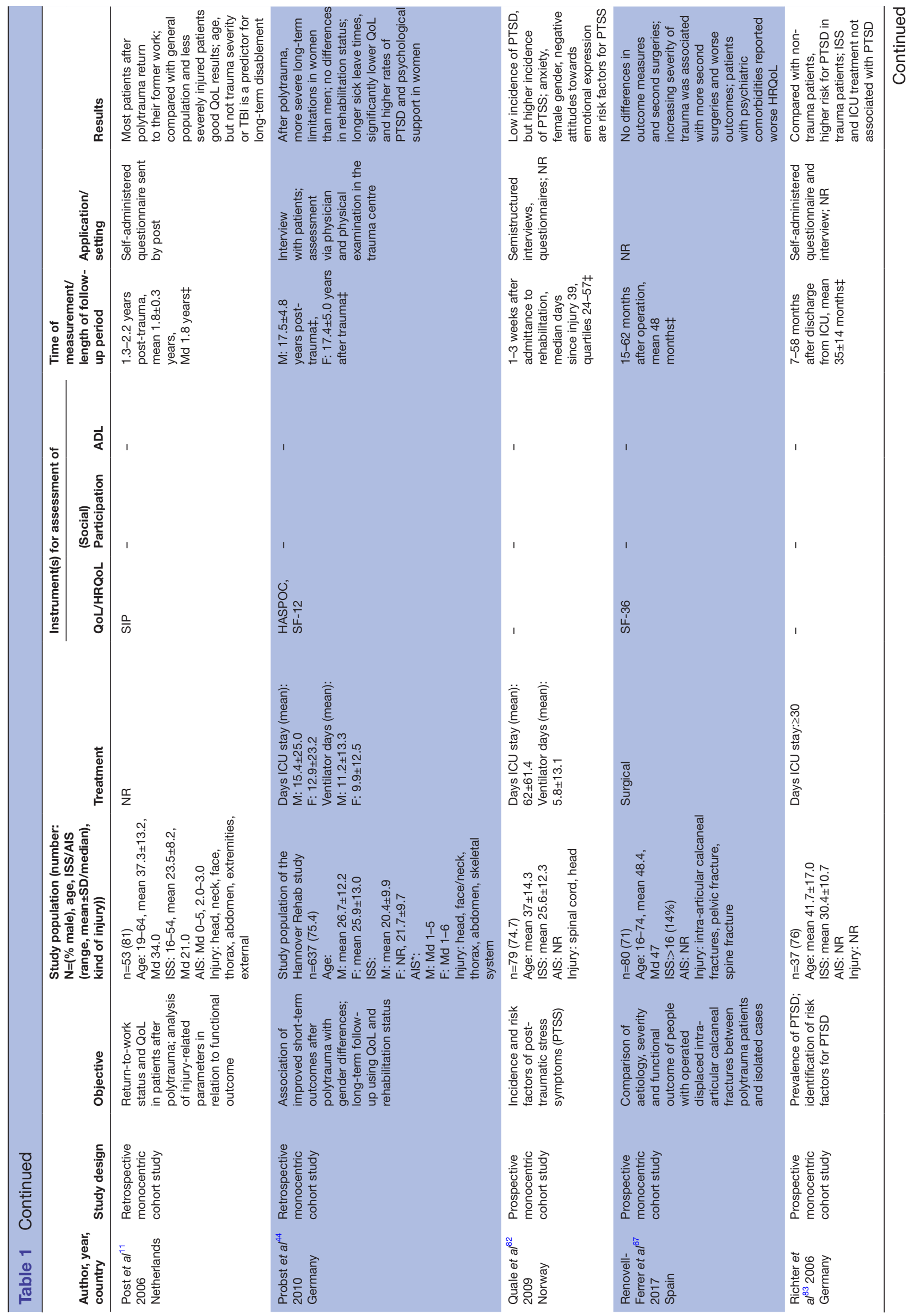




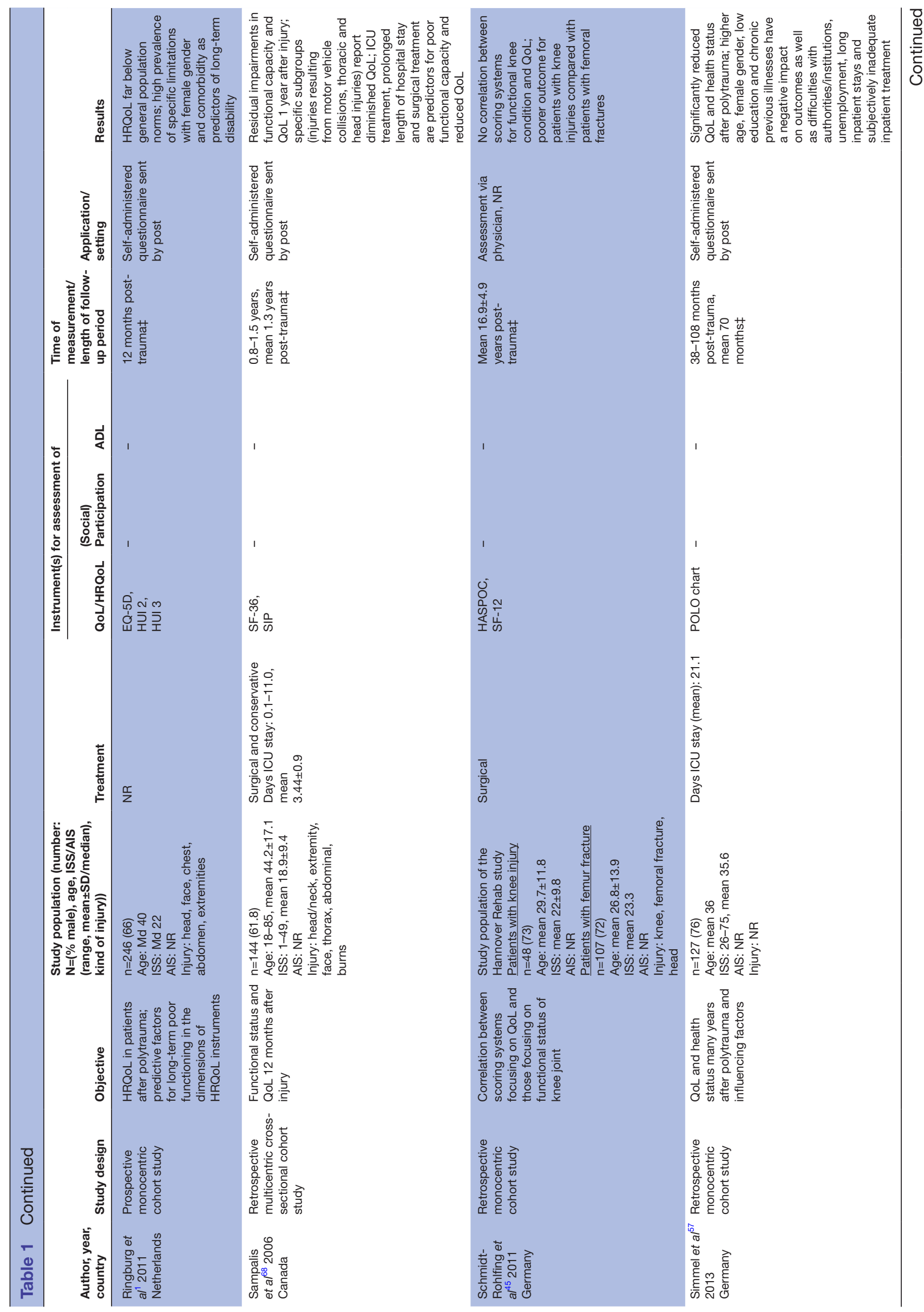









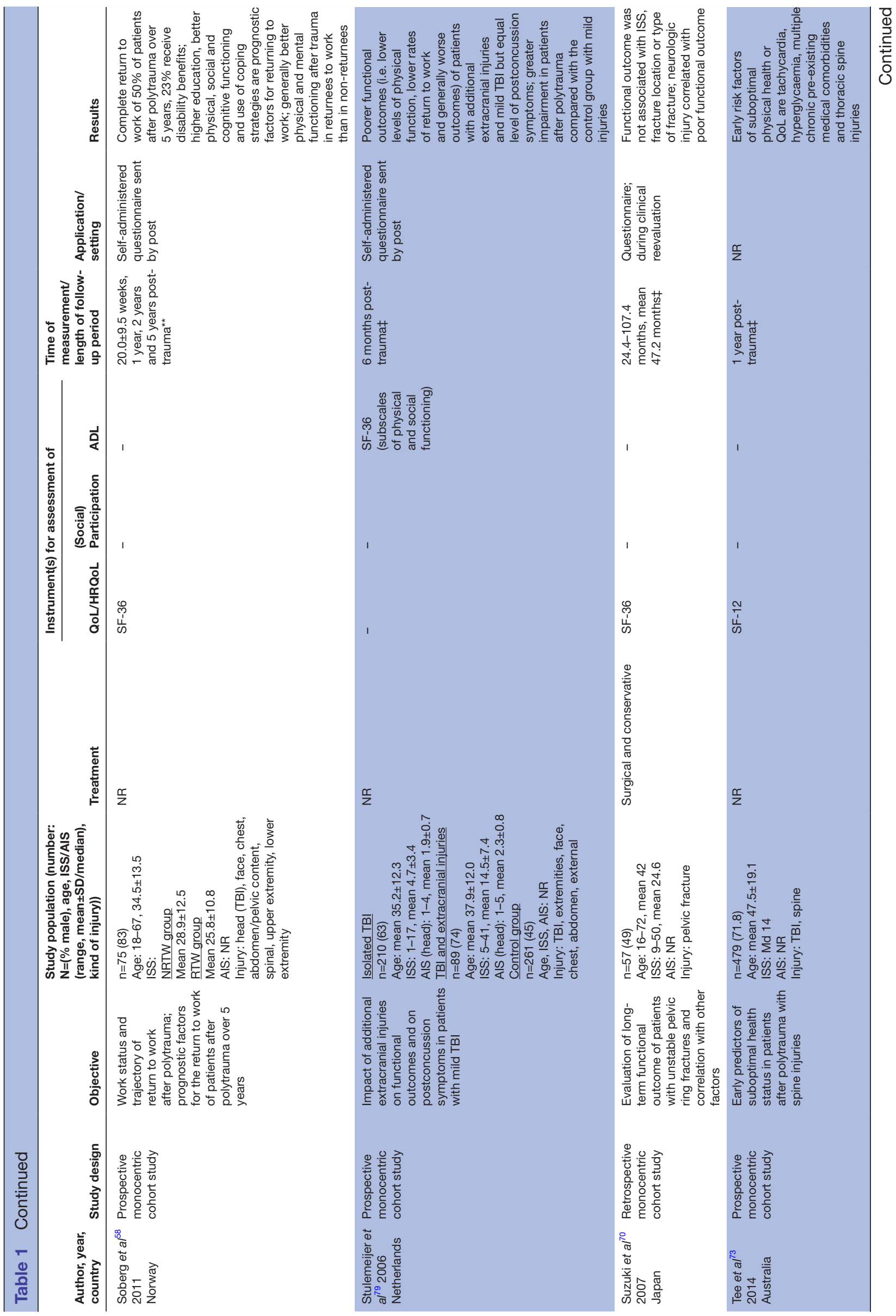









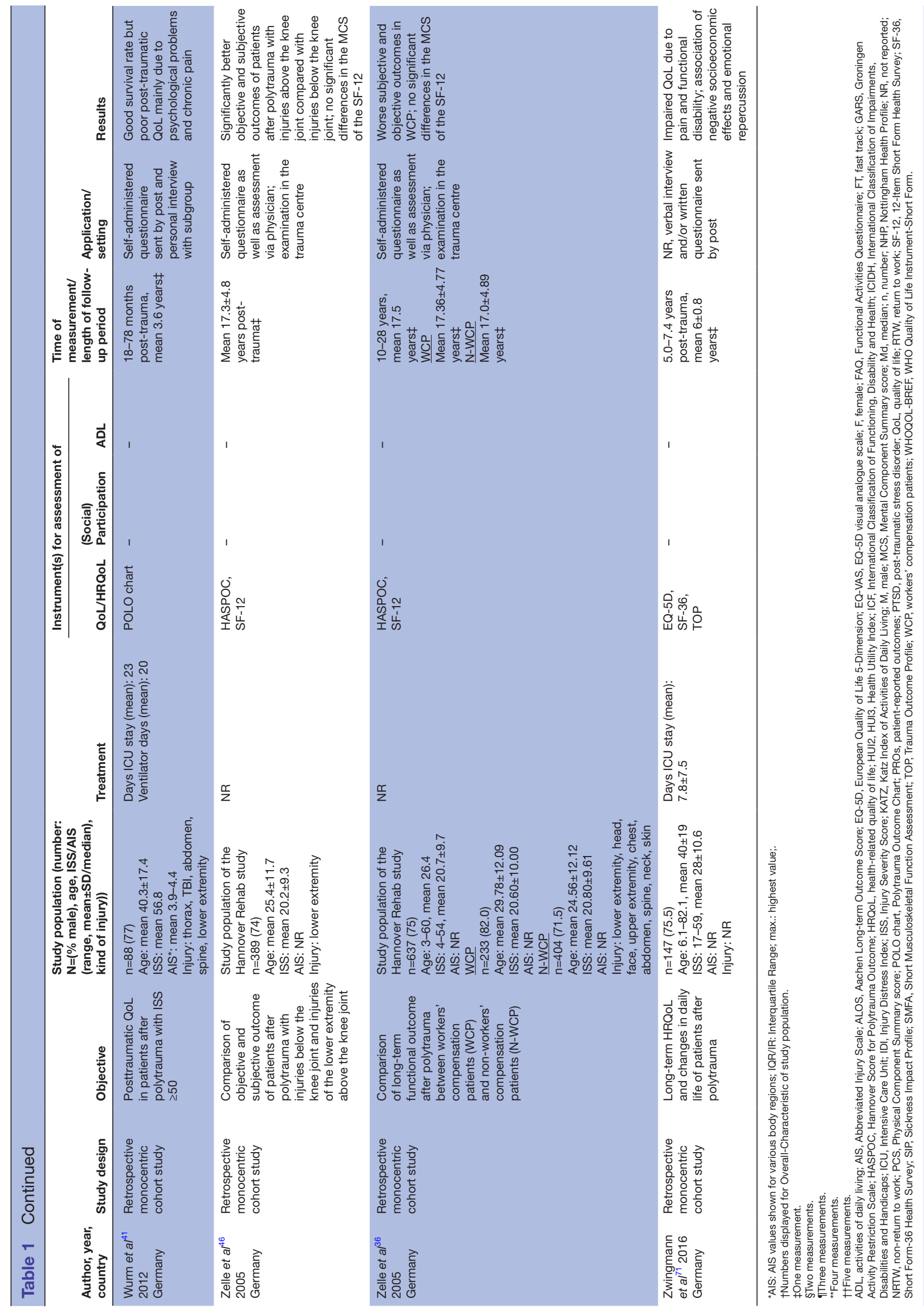


Six publications were related to the Hannover Rehab study. ${ }^{36-46}$ Four reported the results of a polytrauma study project conducted at the University Hospital Basel, which included a subproject of a study project (EK $159 / 02$ ) and a polytrauma cohort. ${ }^{4-50}$ Study projects at the University Medical Centre Utrecht displayed almost identical recruitment periods and locations (Holtslag et al: ${ }^{51} 52$ January 1999 to December 2000, Holtslag et $a l:^{53}{ }^{54}$ January 1999 to January 2001, ${ }^{53}{ }^{54}$ Holtslag et $a l^{53}$ analysed a subgroup out of $n=335$ participants; ${ }^{53}$ Holtslag et $\mathrm{al}^{54}$ additionally included a group 'Fatalities'. ${ }^{54}$ Two publications ${ }^{55} 56$ used the same data collection but addressed different research questions (CIHR, grants no. MOP-62873, FRSQ grant no. 3255). The publication by Sirois $e t a \bar{l}^{5}$ is the original study, ${ }^{56}$ the publication by Ouellet $e t a b^{55}$ is a secondary analysis. ${ }^{55}$ Three publications comprised patients treated at the Murnau Trauma Centre from 2000 to 2005 and recorded in the TraumaRegister DGU® ${ }^{40} 4157$ The publication by von Rüden et at0 and Wurm et $a l^{41}$ reported on the same investigation of a group of severely injured patients with an ISS $>50$; Simmel $e t a l^{77}$ analysed those patients with an ISS $>25 .^{57}$ Soberg et $a p^{58}$ investigated the same research question as Soberg et $a \tilde{l}^{9}$ with a follow-up of 5 years (table 1 ).

More than half of the publications appeared between 2005 and 2009; the number of annual publications seems to be decreasing since 2015 . Table 1 provides an overview of the included publications.

\section{Instruments used to assess HRQOL}

In total, 15 different tools were used to assess HRQoL during follow-up after polytrauma. Of those, six were generic instruments: Short Form-36 Health Survey (SF$36, \mathrm{n}=21,39 \%),{ }^{35} 3847-505358-71$ 12-Item Short Form Health Survey (SF-12, n=12, 22\%), $363742-46555672-74$ Nottingham Health Profile $(\mathrm{n}=4,7 \%),{ }^{47-50}$ Sickness Impact Profile (SIP, n=4, 7\%), ${ }^{11} 515368$ Short Musculoskeletal Function Assessment (SMFA, $\mathrm{n}=1,2 \%)^{75}$ and WHO Quality of Life Instrument-Short Form (WHOQOL-BREF, n=1, $2 \%) .{ }^{75}$ In addition, four preference-based tools were applied: European Quality of Life 5-Dimension (EQ$5 \mathrm{D}, \mathrm{n}=9,17 \%),{ }^{17}{ }^{47-50} 525471$ EQ-6D $(\mathrm{n}=1,2 \%),{ }^{34}$ Health Utility Index Mark 2 (HUI 2, $n=1,2 \%)^{1}$ and HUI $3(n=1$, $2 \%) .{ }^{1}$ Three trauma-specific instruments were used: Hannover Score for Polytrauma Outcome (HASPOC, $\mathrm{n}=6,11 \%),{ }^{36}{ }^{42-46}$ Trauma Outcome Profile (TOP, $(\mathrm{n}=4$, 7\% $)^{4745} 5071$ and Aachen Long-term Outcome Score (ALOS, $\mathrm{n}=1,2 \%) .{ }^{47}$ The Polytrauma Outcome Chart (POLO Chart, $\mathrm{n}=6,11 \%$ ) $^{39-41577677}$ was used as a modular instrument consisting of the Glasgow Outcome Profile, SF-36, EQ-5D and TOP. The International Classification of Impairments, Disabilities and Handicaps (ICIDH) was reported in one publication $(\mathrm{n}=1,2 \%) .{ }^{78}$ Fifteen publications combined two to five different instruments to assess HRQoL. ${ }^{136} 42-5053687175$

In some publications $(\mathrm{n}=5)$, instruments to assess HRQoL were only used partially (e.g. solely the mental or physical part, or selected subscales of the SF-36 or SF-12, chapter 'Disability' of the ICIDH). ${ }^{35} 55567278$ Six publications conducted a retrospective collection of HRQoL via SF-36, SF-12, EQ-5D and TOP capturing the pretrauma status. ${ }^{387-50} 74$

\section{Instruments used to assess ADL}

ADL was measured by different generic instruments: Groningen Activity Restriction Scale (GARS), ${ }^{53}$ Functional Activities Questionnaire (FAQ) ${ }^{64}$ Katz Index of Activities of Daily Living (KATZ ADL) ${ }^{64}$ and Barthel Index (BI) (each $\mathrm{n}=1,2 \%) .{ }^{39}$ The $\mathrm{SF}-36$ subscales of physical and social functioning $(\mathrm{n}=1,2 \%)^{79}$ were also used to record ADL. Two publications employed self-designed questions. ${ }^{735}$ Most frequently $(\mathrm{n}=5)$, a single instrument was applied to assess ADL. ${ }^{735} 395379$

\section{Instruments used to assess (social) participation}

One publication reported the assessment of participation by self-designed questions covering return to sports and work. ${ }^{53}$

Table 2 displays the number of publications and the instruments used to assess HRQoL, ADL and (social) participation.

\section{Application of instruments}

A postal survey was most often used to assess HRQoL, ADL and (social) participation $(\mathrm{n}=17) .{ }^{11} 3447-5357586872757779$ Next in frequency were telephone interviews $(\mathrm{n}=5), 3537555680$ expert assessments $(\mathrm{n}=2),{ }^{45} 64$ face-to-face interview $(\mathrm{n}=1)^{81}$ and combinations of those $(n=16) .{ }^{7363840414344465960666971748283}$ The research settings were: trauma centre, ${ }^{3643444684}$ outpatient clinic, ${ }^{626578}$ hospital, ${ }^{39}$ medical centre or place of patient's residence, ${ }^{64}$ hospital and home. ${ }^{74}$ In four publications, no information regarding the application of instruments was provided. ${ }^{425467} 73$ Relatives or proxies were reported in five publications. ${ }^{37} 52535663$ While most instruments are used with several data collection methods and survey settings, the HASPOC, where reported, is only recorded in the trauma centre and is assessed by a physician in addition to the respondent.

\section{Measurements during follow-up}

PROs mentioned above were most frequently recorded at a single time point $(\mathrm{n}=47) .{ }^{1} 711$ 34-36 39-47 49-57 60-64 66-73 75-84 Few publications reported two $(\mathrm{n}=3),{ }^{486574}$ three $(\mathrm{n}=2),{ }^{3759}$ four or five (each $n=1)^{3858}$ time points of assessment.

\section{Duration of follow-up}

Most often ( $n=13)$, a follow-up of one to one and a half year was reported. ${ }^{1353851-54606265687381}$ Six publications described a follow-up period of over 10 and up to 17.5 years. ${ }^{36} 42-46$ Rarely, shorter follow-up periods of 8 days ${ }^{84}$ to 6 months ${ }^{7479}$ were detected.

\section{Further PROs assessed}

Beyond HRQoL, ADL and (social) participation, assessments of further PROs were reported in the included publications. Most frequently, these comprised function, 
Table 2 Quantitative overview of instruments assessing HRQoL, ADL and (social) participation in $n=54$ publications

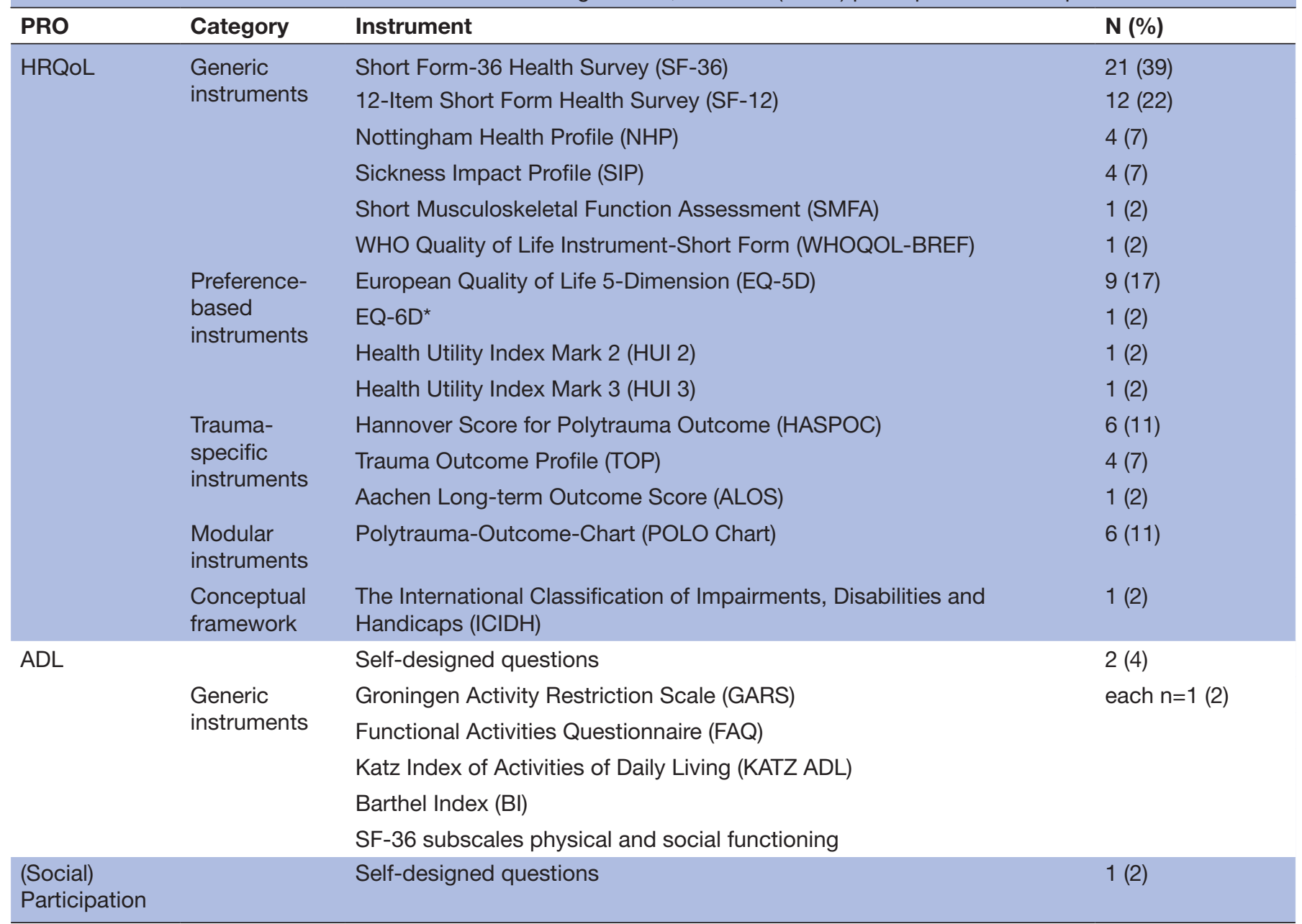

${ }^{*} \mathrm{EQ}-6 \mathrm{D}=\mathrm{EQ}-5 \mathrm{D}$ comprising an additional question capturing a cognitive component (memory, concentration, coherence and IQ). $A D L$, activities of daily living; $H R Q o L$, health-related quality of life; $P R O$, patient-reported outcome.

pain and mental disorders (including depression and/ or depressive symptoms, anxiety and post-traumatic stress disorder (PTSD)). Only few PROs focused on social support, cognition, subjective health status and social network.

Table 3 Quantitative overview of kind and number of further reported PROs in $n=54$ publications

\begin{tabular}{ll}
\hline PRO & N (\%) \\
\hline Function & $19(35)$ \\
Mental disorder & $16(30)$ \\
Pain & $14(26)$ \\
Social support & $7(13)$ \\
Cognition & $6(11)$ \\
Subjective health status & $3(5)$ \\
Social network & $2(4)$ \\
Neuropsychological disorder & $1(2)$ \\
\hline
\end{tabular}

PROs, patient-reported outcomes.
Table 3 provides an overview of the kind and number of further recorded PROs.

\section{Critical appraisal results}

The methodological quality and the risk of bias was appraised using the NICE-checklist for quantitative intervention studies, ${ }^{30} 3876$ the NICE-checklist for quantitative studies reporting correlations and associations, ${ }^{1} 7113134-3740-74$ 77-83 the SIGN-checklist for diagnostic studies ${ }^{32} 3975$ and the Mixed-Method Appraisal Tool. ${ }^{33} 84$

Some methodological weaknesses were identified regarding the selection of the study population, consideration of confounders (e.g. age, sex), data analysis and presentation of results, internal validity and generalisability of study results. ${ }^{340-4345} 50606165677176-78808283$ While most criteria of the critical appraisal were fulfilled, a moderate risk of bias was observed. ${ }^{711} 36-394446-53565759606263666972-75798184$ A low risk of bias was observed in eight publications. ${ }^{135545558646870}$ The results of the critical appraisal are provided in online supplemental file 4 . 


\section{DISCUSSION}

\section{Main findings}

The present systematic review identified 54 publications contributing to the research questions. A great variety was observed among all investigated aspects. HRQoL was the most frequently recorded PRO, and SF-36, SF-12 and EQ-5D were the most frequently applied instruments to assess it. Data on ADL and (social) participation were rarely reported. Most questionnaires were sent out per mail. Measurements were predominantly performed at a single time point, and the follow-up period lasted mainly between one and one and a half year. Function, mental disorders and pain were the most frequently assessed categories of the other PROs.

\section{Instruments for the assessment of HRQoL, ADL and (social) participation}

In 48 of the included publications, HRQoL was assessed-predominantly with generic and preferencebased HRQoL instruments such as SF-36, SF-12, EQ-5D and NHP. Thus, over a long period of time, results are available for the impact of polytrauma on HRQoL and its possible change over time.

Unsurprisingly, the SF-36, one of the oldest and most widely used instrument for assessing HRQoL,${ }^{85}$ is the most frequently reported instrument in publications included in this review. Along with the SF-12, SF tools accounted for $61 \%$ of all identified instruments. This result is supported by observations of other reviews conducted in the field of polytrauma. ${ }^{85-88}$

Considering the use of the different instruments assessing HRQoL by the different trauma groups, it becomes apparent that instruments are used without a clearly recognisable pattern or reason. Similarly, no pattern can be identified to explain the use of the SF-12 instead of the SF-36. No information was provided in this regard in the publications. However, it can be assumed that the reason for using the SF-12 is that it takes less time to administer than the SF-36. In 1999, an international consensus conference on evidence-based guidelines for the systematic evaluation and assessment of HRQoL after polytrauma recommended the use of modular instruments comprising generic and trauma-specific aspects. ${ }^{89}$ Generic instruments have been applied continuously over a long time period, have been translated into different languages and can be applied regardless of the underlying disease. They are suitable for assessing HRQoL after polytrauma since it can affect different body regions, show different injury patterns and lead to a variety of complications. In contrast, trauma-specific instruments capture targeted relevant problems and measure the longitudinal change of HRQoL. ${ }^{90}$ Despite the recommendation, the POLO Chart is the only modular instrument comprising generic and trauma-specific aspects reported in the included publications ${ }^{90}$ HASPOC, TOP and ALOS were the trauma-specific tools used. HASPOC is an instrument designed to evaluate the quality of rehabilitation. Since it comprises instruments assessing inter alia HRQoL, ADL and function, ${ }^{91}{ }^{92}$ we decided to subsume it into the category 'HRQoL'.

Apart from assessing HRQoL, we were particularly interested in the measurement of ADL and social participation. Regarding the assessment of ADL, five different instruments and self-designed questions in six publications were observed in our review. (Social) participation was only reported once by Holtslag et a $\tilde{p}^{3}$. In summary, it was notable that ADL and (social) participation after polytrauma were seldom assessed. One reason might be that measures of HRQoL or function already include several questions related to ADL and (social) participation. Predominantly, (social) participation is researched in people with brain or spinal cord injuries. A general understanding and clear definition of the participatory construct is still missing, which might be another reason for the low reporting rates of (social) participation. It has been argued that (social) participation should be one of the main aspects in rehabilitation after polytrauma, ${ }^{93}$ besides survival and function and there are a number of instruments available to assess this PRO. ${ }^{94-96}$ This could also be assumed for ADL.

\section{Application of instruments}

Most frequently, a postal questionnaire was used. Compared with personal interviews, questionnaires sent by mail are quicker and less expensive. ${ }^{97}$ In addition, potential bias introduced by an interviewer is excluded. However, it is not possible to verify the person answering the questionnaire, comprehension questions cannot be clarified, the full completion of the questionnaire cannot be guaranteed and the proportion of non-responders is higher. ${ }^{97}$ However, other methods of data collection like personal or telephone interviews also have limitations (e.g. influence of the interviewer on the person being interviewed) ${ }^{97}$ thus all data collection methods may incorporate (different) biases. The consultation of a proxy answering the questions was rarely reported. Injuries, for example, traumatic brain injuries (TBI), may require the use of a proxy and could enable the collection of outcome data after polytrauma, despite a risk of bias. ${ }^{97} 98$ The present systematic review excluded publications reporting single or mono injuries like single TBIs, which might be the reason only few publications including proxies were detected.

The retrospective assessment of the pretrauma situation helps enable a comparison of results and obtain a holistic view of the outcome after an injury. Gross et al 4850 as well as Gross and Amsler ${ }^{49}$ measured prefracture level of HRQoL over 2 years after trauma. ${ }^{4-50}$ However, there are limitations to this approach: memories of the pretraumatic situation can be distorted by various circumstances, which might increase the risk of recall bias. ${ }^{99}$ Large population screenings or the use of population norms might help to evaluate the pretraumatic state of HRQoL. ${ }^{18}{ }^{47}$ Baseline assessments should ideally be made in the first week after the event. However, this is not always possible due to the severity of the injury. Another 
limitation might be that some instruments are not suitable for use in hospital. For example, changed behaviour patterns measured by the SIP can also result from the very fact of being an inpatient. Apart from HRQoL, functional recovery is also of great interest and an important factor for evaluating outcomes after a polytrauma. In comparison to HRQoL and due to better quantification, the retrospective evaluation of function is more feasible. ${ }^{18}$

Most of the included publications reported a single assessment of the PROs. However, the course of recovery cannot be derived from a single measurement. The aforementioned consensus conference recommended measurements at 3,12 and 24 months after the event. ${ }^{17}$ Other groups suggested assessments of PROs after 1, 2, 4 and 12 months ${ }^{100}$ or 6 and 12 months after the injury, and beyond 12 months in case of longer rehabilitation needs. $^{13}$

The most frequently reported follow-up period were one to one and a half year. Six publications conducted follow-up periods of more than 10 years.

\section{Further PROs assessed}

Further reported PROs assessed mainly function, mental disorders and pain-outcomes that are highly affected by polytrauma. Social support, subjective health status, cognition or social network were rarely recorded. This might be explained as follows: instruments assessing HRQoL mainly capture subjective health status. While cognition is frequently affected by brain injuries, publications reporting study populations with single brain injuries were excluded from this review. Social network and social support seem to influence recovery and return to work after trauma ${ }^{101} 102$ and should therefore receive more attention in future research.

\section{Recommendations for the assessment of PROs}

The existing recommendations for the use and application of instruments-as well as time points of assessments and outcomes to be measured after polytrauma-differ substantially, ${ }^{13} 17$ but there are attempts to standardise outcome measurements. ${ }^{18}$ Classification systems might be helpful for a standardised assessment of PROs, facilitating the adequate selection of instruments for a specific research objective. ${ }^{23}$ The internet platform PROMISPatient-Reported Outcomes Measurement Information System-provides research tools and is continuously updated with the latest developments and newly translated instruments. ${ }^{103}$ An important step towards a standardised approach of collecting HRQoL was made in the TraumaRegister DGU ${ }^{\circledR}$ by the implementation of HRQoL assessment with the SF-12. ${ }^{14}$

Furthermore, several groups have focused on the definition of special outcome variables to be recorded as default parameters. Hoffman et $a l^{20}$ recommended the development of a 'minimum data set' based on the ICF. ${ }^{20}$ A core outcome set relevant for the respective outcome could be defined. This procedure could guide decisionmaking for the collection and presentation of outcomes in studies. ${ }^{22}$ In addition, ICF linking enabling a check of which ICF components are mapped by an instrument could support the tool selection for particular research questions. ${ }^{1619}$ Other authors also support the idea of core outcome sets. ${ }^{21} 24$

\section{Strengths and limitations}

This review was conducted thoroughly based on a registered protocol in line with the PRISMA-P quality and the PRISMA statement requirements. We provide a broad overview of instruments used for the collection of HRQoL, ADL and (social) participation, along with information on their application. In addition, this study offers an overview on further PROs reported in the context of polytrauma. First efforts to standardise the collection of PROs have been achieved to optimise comparability of outcomes, but further consistency between central players (e.g. trauma registers) is needed. Therefore, this review encourages further improvement in the assessment of PROs after polytrauma.

The present systematic review has some limitations. Selection bias can be assumed as the search was restricted by the search period and language. However, we performed backward citation tracking and saw that only a few additional articles could be included. Our study only included English and German language literature and thus does not provide an insight into published results in other languages. Therefore, it cannot be ruled out that relevant publications from low-income and middle-income countries containing local results in local languages were not included. However, we assume that scientific articles are predominantly published in English; thus, the results presented here should give a comprehensive impression related to the research questions of this systematic review.

We did not use the term 'major trauma'. Therefore, we cannot rule out that relevant publications reporting major trauma were not included. However, major trauma seemed to be increasingly mentioned in connection with single and psychological trauma-neither of which met the inclusion criteria of our systematic review. We screened systematic reviews and meta-analyses to identify further appropriate studies and would have included publications reporting major trauma if they fulfilled the inclusion criteria of this systematic review. Still, we believe that the non-use of the term 'major trauma' has no impact on the results of this systematic review and the answers to the research questions.

\section{CONCLUSION}

The present review reveals variations across study findings, which impairs the comparability of outcomes after polytrauma. To improve this situation, a more standardised approach for recording PROs should be established. First efforts have been initiated, but further alignment between the central players, such as the trauma registers, is required. Continuous collection of core outcomes 
during the regeneration of people with polytrauma could create the basis for a targeted use of treatments and their adaptation to the results of the outcome measurement. Moreover, there appears to be little research on (social) participation and on further PROs like social support and social network. PROs need more attention in polytraumarelated outcome research. After all, we need to know the patients' perspectives on relevant outcomes after polytrauma so as to consider their needs when providing health services.

\section{Author affiliations}

${ }^{1}$ Institute for Health Services Research and Health Economics, Centre for Health and Society, Medical Faculty and University Hospital Düsseldorf, Heinrich-HeineUniversity Düsseldorf, Düsseldorf, Germany

${ }^{2}$ Fliedner Fachhochschule Düsseldorf, University of Applied Sciences, Düsseldorf, Germany

${ }^{3}$ Paracelsus Medical University, Institute of Nursing Science and Practice, Salzburg, Austria

${ }^{4}$ Institute for Health Services Research and Health Economics, German Diabetes Center, Leibniz Center for Diabetes Research at Heinrich-Heine-University

Düsseldorf, Düsseldorf, Germany

${ }^{5}$ Cochrane Metabolic and Endocrine Disorders Group, Institute of General Practice, Faculty of Medicine, Heinrich-Heine-University Düsseldorf, Düsseldorf, Germany

${ }^{6}$ Department of Trauma, Orthopaedics and Hand Surgery, Städt. Klinikum Solingen, Solingen, Germany

${ }^{7}$ Department of Orthopaedics and Traumatology, University Hospital Düsseldorf, Düsseldorf, Germany

${ }^{8} \mathrm{AUC}$ - Academy for Trauma Surgery GmbH, München, Germany

Contributors $\mathrm{Al}$ is the guarantor. M-IM, MR, SK, IG, SA, and AH-F developed the search strategy. MR, SK, IG, SA, KM, AH-F, MI-M, SF, JS, JW, and Al contributed to the development of the selection criteria, the risk of bias assessment strategy, and data extraction criteria. MR, SK, IG, KM, SOB, AH-F, and Al conducted the screenings. The critical appraisal was performed by MR, SK, IG, KM, and SOB. Data extraction was carried out by MR, IG, and CW. MR, SK, IG, SA, and Al drafted the manuscript. MR, SK, IG, SA, KM, SOB, AH-F, M-IM, CW, SF, JS, JW, and AI read the manuscript, provided feedback, and approved the final version.

Funding This work was supported by the Academy for Trauma Surgery GmbH (AUC). The funding supported the conduct of this systematic review. There is no award or grant number for this funding.

Competing interests JS was executive secretary of the Academy for Trauma Surgery $\mathrm{GmbH}$ (AUC). The authors declare that they have no competing interests.

Patient consent for publication Not required.

Provenance and peer review Not commissioned; externally peer reviewed.

Data availability statement № data are available.

Supplemental material This content has been supplied by the author(s). It has not been vetted by BMJ Publishing Group Limited (BMJ) and may not have been peer-reviewed. Any opinions or recommendations discussed are solely those of the author(s) and are not endorsed by BMJ. BMJ disclaims all liability and responsibility arising from any reliance placed on the content. Where the content includes any translated material, BMJ does not warrant the accuracy and reliability of the translations (including but not limited to local regulations, clinical guidelines, terminology, drug names and drug dosages), and is not responsible for any error and/or omissions arising from translation and adaptation or otherwise.

Open access This is an open access article distributed in accordance with the Creative Commons Attribution Non Commercial (CC BY-NC 4.0) license, which permits others to distribute, remix, adapt, build upon this work non-commercially, and license their derivative works on different terms, provided the original work is properly cited, appropriate credit is given, any changes made indicated, and the use is non-commercial. See: http://creativecommons.org/licenses/by-nc/4.0/.

\section{ORCID iD}

Michaela Ritschel http://orcid.org/0000-0001-8686-7956
REFERENCES

1 Ringburg AN, Polinder S, van lerland MCP, et al. Prevalence and prognostic factors of disability after major trauma. J Trauma 2011;70:916-22.

2 Paffrath T, Lefering R, Flohé S. How to define severely injured patients? -An Injury Severity Score (ISS) based approach alone is not sufficient. Injury 2014;45:S64-9.

3 Mörsdorf P, Becker S, Holstein J. [Quality of life after multiple trauma]. Chirurg 2014;85:208-14.

4 Deutsche Gesellschaft für Unfallchirurgie eV. [Weißbuch Schwerverletztenversorgung], 2019. Available: https://www.dguonline.de/q-s/schwerverletzte/weissbuch-schwerverletztenvers orgung.html

5 Sektion Notfall- \& Intensivmedizin \& Schwerverletztenversorgung der Deutschen Gesellschaft für Unfallchirurgie e.V. und AUC Akademie der Unfallchirurgie GmbH. [TraumaRegister DGU® - Jahresbericht 2020], 2020. Available: http://www.traumaregisterdgu.de/fileadmin/user_upload/traumaregister-dgu.de/docs/ Downloads/Jahresbericht_2020.pdf

6 Pape-Köhler CIA, Simanski C, Nienaber U, et al. External factors and the incidence of severe trauma: time, date, season and moon. Injury 2014;45 Suppl 3:S93-9.

7 Vles WJ, Steyerberg EW, Essink-Bot M-L, et al. Prevalence and determinants of disabilities and return to work after major trauma. $J$ Trauma 2005;58:126-35.

8 Debus F, Lefering R, Frink M, et al. Numbers of severely injured patients in Germany. A retrospective analysis from the DGU (German Society for trauma surgery) trauma registry. Dtsch Arztebl Int 2015;112:823-9.

9 Hayes JA, Black NA, Jenkinson C, et al. Outcome measures for adult critical care: a systematic review. Health Technol Assess 2000;4:1-111.

10 Haeusler J-MC, Tobler B, Arnet B, et al. Pilot study on the comprehensive economic costs of major trauma: consequential costs are well in excess of medical costs. J Trauma 2006;61:723-31.

11 Post RB, van der Sluis CK, Ten Duis HJ. Return to work and quality of life in severely injured patients. Disabil Rehabil 2006;28:1399-404.

12 Sittaro NA, Lohse R, Panzica M, et al. [Hannover-polytraumalongterm-study HPLS]. Versicherungsmedizin 2007;59:20-5.

13 Ardolino A, Sleat G, Willett K. Outcome measurements in major trauma--results of a consensus meeting. Injury 2012;43:1662-6.

14 Kamp O, Pfeifer R, Ritschel M, et al. Polytrauma outcome: implementation of health-related quality of life assessment into the German trauma registry. Eur J Trauma Emerg Surg 2021;47:869874.

15 Farin E. ["Teilhabe" (social participation) of patients in health care research: relations to similar concepts and overview of assessment instruments]. Gesundheitswesen 2011;73:e1-11.

16 Ballert CS, Hopfe M, Kus S, et al. Using the refined ICF linking rules to compare the content of existing instruments and assessments: a systematic review and exemplary analysis of instruments measuring participation. Disabil Rehabil 2019;41:584-600.

17 Bouillon B, Kreder HJ, Eypasch E, et al. Quality of life in patients with multiple injuries--basic issues, assessment, and recommendations. Restor Neurol Neurosci 2002;20:125-34.

18 Cameron PA, Gabbe BJ, McNeil JJ. The importance of quality of survival as an outcome measure for an integrated trauma system. Injury 2006;37:1178-84.

19 Cieza A, Fayed N, Bickenbach J, et al. Refinements of the ICF linking rules to strengthen their potential for establishing comparability of health information. Disabil Rehabil 2019;41:547-583.

20 Hoffman KP, Playford DE, Grill E, et al. Minimum data set to measure rehabilitation needs and health outcome after major trauma: application of an international framework. Eur J Phys Rehabil Med 2016;52:331-46.

21 Prinsen CAC, Vohra S, Rose MR, et al. How to select outcome measurement instruments for outcomes included in a "Core Outcome Set" - a practical guideline. Trials 2016;17:449.

22 Selb M, Escorpizo R, Kostanjsek N, et al. A guide on how to develop an international classification of functioning, disability and health core set. Eur J Phys Rehabil Med 2015;51:105-17.

23 Valderas JM, Alonso J. Patient reported outcome measures: a model-based classification system for research and clinical practice. Qual Life Res 2008;17:1125-35.

24 Williamson PR, Altman DG, Blazeby JM, et al. Developing core outcome sets for clinical trials: issues to consider. Trials 2012;13:132. 
25 Moher D, Liberati A, Tetzlaff J, et al. Preferred reporting items for systematic reviews and meta-analyses: the PRISMA statement. PLoS Med 2009;6:e1000097.

26 Bullinger $M$. [The concept of quality of life in medicine: its history and current relevance]. Z Evid Fortbild Qual Gesundhwes 2014;108:97-103.

27 Deshpande PR, Rajan S, Sudeepthi BL, et al. Patient-Reported outcomes: a new era in clinical research. Perspect Clin Res 2011;2:137-44.

28 Gnass I, Ritschel M, Andrich S, et al. Assessment of patientreported outcomes after polytrauma: protocol for a systematic review. BMJ Open 2018;8:e017571.

29 The Cochrane Collaboration. Cochrane Handbook for systematic reviews of interventions version 5.1.0, 2011. Available: http:// handbook.cochrane.org

30 National Institute for Health and Care Excellence (NICE). Nice appendix $\mathrm{F}$ quality appraisal checklist - quantitative intervention studies, 2016. Available: https://www.nice.org.uk/process/pmg4/ chapter/appendix-f-quality-appraisal-checklist-quantitativeintervention-studies\#notes-on-the-use-of-the-quantitative-studieschecklist

31 National Institute for Health and Care Excellence (NICE). Nice appendix $G$ quality appraisal checklist - quantitative studies reporting correlations and associations, 2016. Available: https:// www.nice.org.uk/process/pmg4/chapter/appendix-g-qualityappraisal-checklist-quantitative-studies-reporting-correlationsand

32 Scottish Intercollegiate Guidelines Network (SIGN). Sign methodology checklist 5: studies of diagnostic accuracy, 2016. Available: http://www.google.de/url?sa=t\&rct=j\&q=\&esrc=s\& source $=$ web $\& c d=4 \& c a d=$ rja $\&$ uact $=8 \&$ sq $i=2 \& v e d=0$ ahUKEwi Yp9P824bVAhWLJIAKHSmKDZcQFgg7MAM\&url=http\%3A\% 2F\%2Fwww.sign.ac.uk\%2Fassets\%2Fchecklist_for_diagnostic accuracy-studies.doc\&usg=AFQjCNETExuNUQoaEFhPoPXgk5uwyXtGQ

33 Pace R, Pluye P, Bartlett G, et al. Testing the reliability and efficiency of the pilot mixed methods appraisal tool (MMAT) for systematic mixed studies review. Int J Nurs Stud 2012;49:47-53.

34 Gribnau AJG, van Hensbroek PB, Haverlag R, et al. U-Shaped sacral fractures: surgical treatment and quality of life. Injury 2009;40:1040-8.

35 McCarthy ML, Dikmen SS, Langlois JA, et al. Self-Reported psychosocial health among adults with traumatic brain injury. Arch Phys Med Rehabil 2006;87:953-61.

36 Zelle BA, Panzica M, Vogt MT, et al. Influence of workers compensation eligibility upon functional recovery 10 to 28 years after polytrauma. Am J Surg 2005b;190:30-6.

37 Marasco S, Lee G, Summerhayes R, et al. Quality of life after major trauma with multiple rib fractures. Injury 2015;46:61-5.

38 Bouman AIE, Hemmen B, Evers SMAA, et al. Effects of an integrated 'fast track' rehabilitation service for multi-trauma patients: a non-randomized clinical trial in the Netherlands. PLoS One 2017;12:e0170047.

39 Lefering R, Tecic T, Schmidt Y, et al. Quality of life after multiple trauma: validation and population norm of the Polytrauma outcome (polo) chart. Eur J Trauma Emerg Surg 2012;38:403-15.

40 von Rüden $\mathrm{C}$, Woltmann $\mathrm{A}$, Röse $\mathrm{M}$, et al. Outcome after severe multiple trauma: a retrospective analysis. J Trauma Manag Outcomes 2013;7:4

41 Wurm S, Röse M, von Rüden C, et al. [Severe polytrauma with an ISS $\geq 50$ ]. Z Orthop Unfall 2012;150:296-301.

42 Andruszkow $\mathrm{H}$, Probst $\mathrm{C}$, Grün O, et al. Does additional head trauma affect the long-term outcome after upper extremity trauma in multiple traumatized patients: is there an additional effect of traumatic brain injury? Clin Orthop Relat Res 2013;471:2899-905.

43 Dienstknecht T, Pfeifer R, Horst K, et al. The long-term clinical outcome after pelvic ring injuries. Bone Joint $J$ 2013;95-B:548-53.

44 Probst C, Zelle B, Panzica M, et al. Clinical re-examination 10 or more years after polytrauma: is there a gender related difference? $\mathrm{J}$ Trauma 2010;68:706-11.

45 Schmidt-Rohlfing B, Pfeifer R, Kaneshige J, et al. Scoring systems for outcome after knee injuries. Injury 2011;42:271-5.

46 Zelle BA, Brown SR, Panzica M, et al. The impact of injuries below the knee joint on the long-term functional outcome following polytrauma. Injury 2005a;36:169-77.

47 Attenberger C, Amsler F, Gross T. Clinical evaluation of the trauma outcome profile (TOP) in the longer-term follow-up of polytrauma patients. Injury 2012;43:1566-74.

48 Gross T, Attenberger C, Huegli RW, et al. Factors associated with reduced longer-term capacity to work in patients after polytrauma: a Swiss trauma center experience. J Am Coll Surg 2010;211:81-91.
49 Gross T, Amsler F. Prevalence and incidence of longer term pain in survivors of polytrauma. Surgery 2011;150:985-95.

50 Gross T, Schüepp M, Attenberger C, et al. Outcome in polytraumatized patients with and without brain injury. Acta Anaesthesiol Scand 2012;56:1163-74

51 Holtslag HR, Post MW, Lindeman E, et al. Long-term functional health status of severely injured patients. Injury 2007a;38:280-9.

52 Holtslag HR, van Beeck EF, Lindeman E, et al. Determinants of long-term functional consequences after major trauma. J Trauma 2007b;62:919-27.

53 Holtslag H, Buskens E, Rommers C, et al. Long-term outcome after lower extremity injuries in severely injured patients. Eur J Trauma 2006;32:365-73.

54 Holtslag HR, van Beeck EF, Lichtveld RA, et al. Individual and population burdens of major trauma in the Netherlands. Bull World Health Organ 2008;86:111-7

55 Ouellet M-C, Sirois M-J, Lavoie A. Perceived mental health and needs for mental health services following trauma with and without brain injury. J Rehabil Med 2009;41:179-86.

56 Sirois M-J, Dionne CE, Lavoie A. Regional differences in rehabilitation needs, rehabilitation access, and physical outcomes among multiple trauma survivors. Am J Phys Med Rehabil 2009;88:387-98.

57 Simmel S, Drisch S, Haag S, et al. [Long-term results after multiple trauma with ISS $\geq 25$. Outcome and predictors of quality of life]. Chirurg 2013;84:771-9.

58 Soberg HL, Roise O, Bautz-Holter E, et al. Returning to work after severe multiple injuries: multidimensional functioning and the trajectory from injury to work at 5 years. J Trauma 2011;71:425-34

59 Soberg HL, Finset A, Bautz-Holter E, et al. Return to work after severe multiple injuries: a multidimensional approach on status 1 and 2 years postinjury. J Trauma 2007:62:471-81.

60 Abraham CM, Obremskey WT, Song Y, et al. Hospital delirium and psychological distress at 1 year and health-related quality of life after moderate-to-severe traumatic injury without intracranial hemorrhage. Arch Phys Med Rehabil 2014;95:2382-9.

61 Ahrberg AB, Leimcke B, Tiemann AH, et al. Missed foot fractures in polytrauma patients: a retrospective cohort study. Patient Saf Surg 2014;8:10.

62 Baranyi A, Leithgöb O, Kreiner B, et al. Relationship between posttraumatic stress disorder, quality of life, social support, and affective and dissociative status in severely injured accident victims 12 months after trauma. Psychosomatics 2010;51:237-47.

63 Burghofer K, Lackner CK, Stolpe E. [Quality of life 5 years after severe blunt trauma]. Notf Rett Med 2005;8:552-63.

64 Jackson JC, Obremskey W, Bauer R, et al. Long-term cognitive, emotional, and functional outcomes in trauma intensive care unit survivors without intracranial hemorrhage. J Trauma 2007;62:80-8.

65 Lippert-Grüner M, Maegele M, Haverkamp H, et al. Health-Related quality of life during the first year after severe brain trauma with and without polytrauma. Brain Inj 2007;21:451-5.

66 Overgaard M, Høyer CB, Christensen EF. Long-term survival and health-related quality of life 6 to 9 years after trauma. J Trauma 2011;71:435-41.

67 Renovell-Ferrer P, Bertó-Martí X, Diranzo-García J, et al. Functiona outcome after calcaneus fractures: a comparison between polytrauma patients and isolated fractures. Injury 2017;48 Suppl 6:S91-6.

68 Sampalis JS, Liberman M, Davis L, et al. Functional status and quality of life in survivors of injury treated at tertiary trauma centers: what are we neglecting? J Trauma 2006;60:806-13.

69 Sluys K, Häggmark T, Iselius L. Outcome and quality of life 5 years after major trauma. J Trauma 2005;59:223-32.

70 Suzuki T, Shindo M, Soma K, et al. Long-term functional outcome after unstable pelvic ring fracture. J Trauma 2007;63:884-8.

71 Zwingmann J, Hagelschuer P, Langenmair E, et al. Lower healthrelated quality of life in Polytrauma patients: long-term follow-up after over 5 years. Medicine 2016;95:e3515.

72 Archer KR, Abraham CM, Song Y, et al. Cognitive-behavioral determinants of pain and disability two years after traumatic injury: a cross-sectional survey study. J Trauma Acute Care Surg 2012;72:473-9.

73 Tee JW, Chan CHP, Gruen RL, et al. Early predictors of healthrelated quality of life outcomes in polytrauma patients with spine injuries: a level 1 trauma center study. Global Spine J 2014:4:21-32.

74 Williamson OD, Epi GDC, Gabbe BJ, Cameron P, et al. Predictors of moderate or severe pain 6 months after orthopaedic injury: a prospective cohort study. J Orthop Trauma 2009;23:139-44. 
75 van Delft-Schreurs CCHM, van Son MAC, de Jongh MAC, et al. Psychometric properties of the Dutch short musculoskeletal function assessment (SMFA) questionnaire in severely injured patients. Injury 2016;47:2034-40.

76 Christensen MC, Banner C, Lefering R, et al. Quality of life after severe trauma: results from the global trauma trial with recombinant factor VII. J Trauma 2011;70:1524-31.

77 Kaske S, Lefering R, Trentzsch H, et al. Quality of life two years after severe trauma: a single-centre evaluation. Injury 2014;45 Suppl 3:S100-5.

78 Hładki W, Lorkowski J, Trybus M, et al. Quality of life as a result of multiple injury in the aspect of limitations of handicaps--social roles. Przegl Lek 2009;66:134-40.

79 Stulemeijer M, van der Werf SP, Jacobs B, et al. Impact of additional extracranial injuries on outcome after mild traumatic brain injury. $J$ Neurotrauma 2006;23:1561-9.

80 Livingston $\mathrm{DH}$, Tripp T, Biggs $\mathrm{C}$, et al. A fate worse than death? long-term outcome of trauma patients admitted to the surgical intensive care unit. J Trauma 2009;67:341-8.

81 Frénisy $\mathrm{M}-\mathrm{C}$, Bénony $\mathrm{H}$, Chahraoui $\mathrm{K}$, et al. Brain injured patients versus multiple trauma patients: some neurobehavioral and psychopathological aspects. J Trauma 2006;60:1018-26.

82 Quale AJ, Schanke A-K, Frøslie KF, et al. Severity of injury does not have any impact on posttraumatic stress symptoms in severely injured patients. Injury 2009;40:498-505.

83 Richter JC, Waydhas C, Pajonk F-G. Incidence of posttraumatic stress disorder after prolonged surgical intensive care unit treatment. Psychosomatics 2006;47:223-30.

84 Victorson DE, Enders CK, Burnett KF, et al. The injury distress index: development and validation. Arch Phys Med Rehabil 2008;89:1893-902.

85 Hoffman K, Cole E, Playford ED, et al. Health outcome after major trauma: what are we measuring? PLoS One 2014;9:e103082.

86 Grill E, Mittrach R, Müller M. [Systematic review of measurement instruments and concepts used for functioning outcome in multiple trauma]. Unfallchirurg 2010;113:448-55.

87 Khan F, Amatya B, Hoffman K. Systematic review of multidisciplinary rehabilitation in patients with multiple trauma. $\mathrm{Br} J$ Surg 2012;99 Suppl 1:88-96.

88 Hofhuis JGM, Spronk PE. Health-Related quality of life and influence of age after trauma: an overview. J Trauma Acute Care Surg 2014;76:549-56.

89 Neugebauer E, Bouillon B, Bullinger M, et al. Quality of life after multiple trauma--summary and recommendations of the consensus conference. Restor Neurol Neurosci 2002;20:161-7.

90 Pirente N, Bouillon B, Schäfer B. A systematically developed instrument for the assessment of health-related quality of life in multiple injured patients. The Polytrauma outcome (polo) chart. Unfallchirurg 2002;105:413-22.

91 Stalp M, Koch C, Regel G, et al. [Development of a standardized instrument for quantitative and reproducible rehabilitation data assessment after polytrauma (HASPOC)]. Chirurg 2001;72:10.1007/ s001040051312:312-8.

92 Stalp M, Koch C, Ruchholtz S, et al. Standardized outcome evaluation after blunt multiple injuries by scoring systems: a clinical follow-up investigation 2 years after injury. J Trauma 2002;52:1160-8.

93 Simmel S, Bühren V. [Surviving multiple trauma - what comes next?]. Unfallchirurg 2009;112:965-74.

94 Resnik L, Plow MA. Measuring participation as defined by the International classification of functioning, disability and health: an evaluation of existing measures. Arch Phys Med Rehabil 2009;90:856-66.

95 Magasi S, Post MW. A comparative review of contemporary participation measures' psychometric properties and content coverage. Arch Phys Med Rehabil 2010;91:S17-28.

96 Eyssen IC, Steultjens MP, Dekker J, et al. A systematic review of instruments assessing participation: challenges in defining participation. Arch Phys Med Rehabil 2011;92:10.1016/j. apmr.2011.01.006:983-97.

97 Pfaff H, Bentz J, Ommen O. Qualitative und quantitative Methoden der Datengewinnung. In: Schwartz FW, Walter U, Siegrist J, eds. Public Health - Gesundheit und Gesundheitswesen. 3. Auflage. München: Urban \& Fischer, 2012: 451-67.

98 Bitzer EM. Die Perspektive der Patienten - Lebensqualität und Patientenzufriedenheit. In: Schwartz FW, Walter U, Siegrist J, eds. Public health Gesundheit und Gesundheitswesen. 3rd edition. München: Urban \& Fischer, 2012: 485-91.

99 Scholten AC, Haagsma JA, Steyerberg EW, et al. Assessment of pre-injury health-related quality of life: a systematic review. Popul Health Metr 2017;15:10.

100 Van Beeck EF, Larsen CF, Lyons RA, et al. Guidelines for the conduction of follow-up studies measuring injury-related disability. J Trauma 2007;62:534-50.

101 Prang K-H, Berecki-Gisolf J, Newnam S. Recovery from musculoskeletal injury: the role of social support following a transport accident. Health Qual Life Outcomes 2015;13:10.1186/ s12955-015-0291-8.

102 de Graaf MW, Reininga IHF, Heineman E, et al. The development and internal validation of a model to predict functional recovery after trauma. PLoS One 2019;14:e0213510.

103 PROMIS Germany. Dynamic tools to measure health outcomes from the patient perspective. Available: http://promis-germany. de 